\title{
Elit ve Sub-elit Genç Karatecilerin Reaktif Çeviklik ve Planlı Yön Değiştirme Becerilerinin Karşılaștırılması
}

\section{Comparison of the Reactive Agility and Preplanned Change of Direction Abilities of the Elite and Sub Elite Young Karate Players}

\author{
ORIJIINAL ARAŞTIRMA/ \\ ORIGINAL RESEARCH
}

\author{
Mehmet YILDIZ ${ }^{\dagger}$ \\ Rabia ÇİĞİRDİ ${ }^{2}$
}

\author{
${ }^{1}$ Afyon Kocatepe Üniversitesi, Beden \\ Eğitimi ve Spor Yüksekokulu, \\ Afyonkarahisar. \\ http://orcid.org/0000-0003-3481-7775 \\ ${ }^{2}$ Afyon Kocatepe Üniversitesi, Beden \\ Eğitimi ve Spor Yüksekokulu, \\ Afyonkarahisar. \\ http://orcid.org/0000-0003-3481-7775
}

\begin{abstract}
$\ddot{\mathbf{O z}}$
$\mathrm{Bu}$ çalışmanın amacı elit ve sub-elit genç karatecilerin yumruk vuruşlarına göre düzenlenmiş reaktif çeviklik ve planlı yön değiştirme becerilerinin karşılaştırılmasıdır. Çalışmaya on üç elit (yaş: $14.92 \pm 1.65$ yıl, boy: $157.53 \pm 9.07 \mathrm{~cm}$, kilo:52.92 $\pm 9.86 \mathrm{~kg}$ ) ve

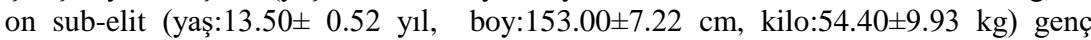
karateci katılmıștır. Sporcuların yumruk atışları esnasındaki reaktif çevikliklerinin belirlenmesi amaciyla kum torbasının dört ayrı noktasına dört kızılötesi sensör yerleştirilmiştir. Sensörlerin üzerinde led 1şık bulunmaktadır. Bu sensörlerden biri araştırmacı tarafından tetiklenerek açılır. Sporcu ışığı aktifleşen ledin altına yumruk atar yumruk atıldığında sensör yumruğu algılar ve diğer ledi yakar. Sporcu toplamda dört ledi söndürdüğünde test sona erer. Sporcu bu testte hangi sensörün aktifleșeceğini bilmemektedir. Her sporcu için farklı rota belirlenmiştir. Planlı yön değiştirme testinde ise bu sefer sporcular hangi sensörün altına sırasıyla yumruk atacaklarını bilmektedir. Startla beraber sırasıyla dört ledin altına yumruk atışı yapıldığında test sona ermiştir. Her iki testin sonucunun gruplar arasında karşılaştırılması amacıyla bağımsız değiş̧ken t testi kullanılmıştır. Testler arasındaki ilişkinin belirlenmesi için Pearson korelasyon analizi uygulanmıştır. Çalışma sonunda elit sporcuların reaktif çeviklik değerleri istatistiksel olarak daha kisa iken $(2.567 \pm 0.50 \mathrm{sn}$. karșin $3.469 \pm 0.77 \mathrm{sn} ., \mathrm{p}<0.05)$, planlı yön değiştirme becerileri arasında anlamlı fark tespit edilememiştir. Bununla beraber, iki test arasında pozitif yönde yüksek bir ilişki tespit edilmiştir $(r=0.874, p<0.05)$. Sonuç olarak; dövüş sporlarında antrenmanlarda reaktif çeviklik çalışmalarına yer verilmesi önerilmektedir.
\end{abstract}

Anahtar Kelimeler: Reaktif Çeviklik, Karate, Yumruk

\begin{abstract}
The purpose of this study was to compare elite and sub-elite young karate players' reactive agility and preplanned change of direction abilities regulated considering their punches. Thirteen elite (age: $14.92 \pm 1.65$ height: $157.53 \pm 9.07 \mathrm{~cm}$, weight: $52.92 \pm 9.86 \mathrm{~kg}$ ) and 10sub-elite (age: $13.50 \pm 0.52$, height: $153.00 \pm 7.22 \mathrm{~cm}$, weight: $54.40 \pm 9.93 \mathrm{~kg}$ ) young karate players participated in the current study. Four infrared sensors were placed on four different points of the sandbag for the purpose of determining reactive agilities of the players during their punching. Led light was present on the sensors. One of these sensors was turned on by the researcher by being triggered. The player punched under the sensor for becoming active, the sensor detected the punch when it was thrown out and it triggered on another sensor. As the player turned off four led lights in total, the test ended. The player did not know which sensor became active in this test. A different course was set for each player. In preplanned change of direction test, the players knew which sensor will be triggered respectively. With the start, when punches were thrown out under four led lights respectively, the test ended. Independent variable t-test was used for comparing the results of two tests among the groups. Pearson correlation analysis was used to determine the relationship between the tests. As a consequence of the study, the reactive agility values of the elite players were statistically lower $(2.567 \pm 0.50 \mathrm{sec}$. vs. $3.469 \pm 0.77 \mathrm{sec}$. $\mathrm{p}<0.05)$ while a meaningful difference was not found between their preplanned change of direction. In addition, there was high positive correlation between two tests $(r=0.874, \mathrm{p}<0.05)$. In conclusion, it was suggested that reactive agility exercises should be included in trainings of the martial sports.
\end{abstract}

Key Words: Reactive Agility, Karate, Punch

\footnotetext{
* Bu çalışma 13-26 Kasım 2017 tarihleri arasında Manisa Celal Bayar Üniversitesi tarafından gerçekleştirilen Dünya Spor Bilimleri Araştırmaları Kongresi'nde sözel bildiri olarak sunulmuştur

† Sorumlu yazar: Mehmet Yildı, mehmetyildiz@aku.edu.tr
} 


\section{GİRIŞ}

Çeviklik hareketleri takım, raket ve dövüş sporları başta olmak üzere birçok spor dalı için çok önemlidir. Uzun yıllar boyunca çeviklik hızlı hareketleri uygulama ve hızlı bir şekilde durup yeniden hızlanma kapasitesi olarak sınıflandırılmıştır (Farrow, Young ve Bruce, 2005; Zemkova, 2016). Genel itibari ile bu tip hareketler rakip oyuncuları aldatmak ya da takip etmek, rakipteki topu almak veya hareket halindeki topa reaksiyon göstermek için kullanılmaktadır (Young, James ve Montgomery, 2002). Çevikliğin ortak bir tanımı olmamasına rağmen (Holmberg, 2009; Jeffreys, 2011; Sheppard ve Young, 2006), sıklıkla hız ve kontrol kaybının en az olduğu efektif ve hızlı (planlı) yön değiştirme kabiliyeti olarak tanımlanır (Barnes, Schilling, Falvo, Weiss ve Creasy, 2007; Young ve Wiley, 2010). Bu tanımalar daha çok motorik özelliklere odaklanmıştır. Bu tip klasik çeviklik test ve çalışmalarında sporcuların alanı, başlangıç noktasını, dönüş noktalarını önceden bilmelerinden dolayı bu becerilerin planlı yön değiştirme (PYD) kabiliyeti olarak tanımlanması daha doğru olacaktır (Young ve Farrow, 2006).

Gerek sportif alanda gerekse bilimsel çalışmalarda çeviklikle ilgili kullanılan bu testlere bakıldığında önceden planlanmış yer değiştirmelerden oluştuğu görülmektedir (Young ve Farrow, 2006). Bu amaçla kolay uygulanabilir ve değerlendirilmesi basit birçok saha testleri geliştirilmiştir. $\mathrm{Bu}$ testler basit birkaç ekipmanla ölçümün yapılmasına ve değerlendirilmesine imkan vermektedir (Karacabey, 2013). Bu tip çalışmalarda koni, çubuk veya basamak gibi engeller kullanılarak kolaylıkla test alanı oluşturulabilmektedir (Young ve Farrow, 2006). Sporda en yaygın kullanılan kapalı beceri çeviklik testlerinin başında T Testi, Pro-Agility Çeviklik Testi, Illinois Çeviklik Testi ve 505 Çeviklik testi gelmektedir. Bu testler spor branşlarına, saha yeterliliğine ve elde bulunan ekipmanlara göre değişim gösterir (Karacabey, 2013). Bu tip çalışmalarda atletik olarak bu sporcuların kapasitesi ölçülebilir fakat hızlı düşünme, çabuk karar verme ve çabuk reaksiyon verme gibi algısal ve karar verme faktörleri ölçülememektedir. Örneğin planlı yön değiştirme becerisi orta seviyede olan bir sporcunun aynı zamanda algılama ve karar verme becerisi çok daha gelişmiş olabilmektedir (Young ve Farrow, 2006). Fakat takım, raket ve dövüş sporlarında sporcular bir uyarana ya da sezinlemeye göre tepki verirler. $\mathrm{Bu}$ durum görsel ve bilişsel faaliyetlerin de işin içine girdiğini göstermektedir. Bu neden dolayı, çeviklik ile ilgili görsel ve bilişsel faaliyetleri de kapsayan yeni tanımlar ortaya çıkmıştır. Örneğin; Sheppard ve Young (2006), çevikliği algısal ve karar verme faktörleri ile yön değiştirmeli koşu altında iki bölüme 
ayırmıştır. Görsel taramanın algısal ve karar verme faktörleri içinde çevikliği etkileyen çok önemli bir unsur olduğu bildirilmiştir (Karacabey, 2013). Takım, raket ve dövüş sporlarında sporcunun alandan elde ettiği görsel bilgiler doğrultusunda yanıtlar vermesi gerekir. Sporcu performansı olarak hızlı ve doğru, görsel ve nöromusküler işlemler önemli bir kabiliyet olarak görülür. Bundan dolayı görsel-motor reaksiyon hızını değerlendirmek ve geliştirmek için birçok cihaz ve sistem (FITLIGHT Trainer, Wayne Saccadic Fixator, Dynavision, Vision Coach, Sanet Vision Integrator, Cybex reactor) geliştirilmiştir (Appelbaum ve Erickson, 2016; Hertel, Denegar, Johnson, Hale ve Buckley, 1999).

Literatürde elit ve sub-elit sporcuların reaktif çeviklik ve planlı yön değiştirme becerilerinin karşılaştıran birçok çalışma bulunmaktadır (Farrow ve ark., 2005; Gabbett ve Benton, 2009; Serpell, Ford ve Young, 2010; Young, Farrow, Pyne, McGregor and Handke, 2011). Bu çalışmalarda gruplar arasında planlı yön değiştirme becerilerinde anlamlı bir fark bulunmazken reaktif yön değiştirme becerilerinin elit sporcularda daha iyi olduğunu bildirmişlerdir. Bununla beraber dövüş sporlarında reaktif çeviklik uygulamaları ile ilgili çok sınırlı bilgileri bulunmaktadır. $\mathrm{Bu}$ çalışmanın amacı elit ve sub-elit genç karate sporcularının reaktif çeviklik ve planlı yön değiş̧tirme becerilerinin karşılaş̧ırılmasıdır.

\section{YÖNTEM}

\section{Araştırma Grubu}

Çalışmaya 13 elit (yaş:14.92 \pm 1.65 yıl, boy: $157.53 \pm 9.07 \mathrm{~cm}$, kilo:52.92 $\pm 9.86 \mathrm{~kg}$ ) ve 10 sub-elit (yaş: $13.50 \pm 0.52$ y1l, boy: $153.00 \pm 7.22 \mathrm{~cm}$, kilo:54.40 $\pm 9.93 \mathrm{~kg}$ ) genç karateci katılmıştır. Elit karateciler Afyonkarahisar'da bulunan farklı kulüplerde yarışan ve Türkiye derecesi olan sporculardan seçilirken, sub-elit karateciler aynı kulüplerde yarışan fakat Türkiye derecesi bulunmayan sporculardan seçilmiştir. Tüm katılımcılar gönüllü olur formunu doldurmuştur.

\section{İşlem yolu}

Sporcuların yumruk atışları esnasındaki reaktif çevikliklerinin belirlenmesi amacıyla kum torbasının dört ayrı noktasına ( $30^{0}$ açı ile) dört kızılötesi sensör yerleştirilmiştir. Sensörlerin üzerinde led 1şık bulunmaktadır. Bu sensörlerden biri araştırmacı tarafından tetiklenerek açılır. 
Sporcu 1şı̆̆ı aktifleşen ledin altına yumruk atar yumruk atıldığında kızılötesi sensör yumruğu algilar ve diğer ledi yakar. Sporcu toplamda dört ledi söndürdüğünde test sona erer. Sporcu bu testte hangi sensörün aktifleşeceğini bilmemektedir. Her sporcu için farklı rota belirlenmiştir. Planlı yön değiştirme testinde ise bu sefer sporcular hangi sensörün altına sırasıyla vuracaklarını bilmektedir. Startla beraber sırasıyla dört ledin altına yumruk atışı yapıldığında test sona ermiştir.

Tüm testler toplam dört gün, sabah saat 10:30 ile 12.30 arasında kulübün spor salonunda gerçekleştirilmiştir. Tüm katılımcılara sabah her zamanki alışkanlıklarına göre kahvaltı yapmaları ve normal sıvı alımı gerçekleştirmeleri söylenmiştir. Ayrıca ölçümlerden bir gün önce ağır antrenmandan uzak durmaları istenmiştir. Ölçümlerden önce katılımcıların tanımlayıcı istatistik olarak yaş, boy ve vücut ağırlığı değerleri alınmıştır. Daha sonra katılımcılar $10 \mathrm{dk}$. submaksimal aerobik egzersiz (jogging) daha sonra $10 \mathrm{dk}$. dinamik stretching yapmışlardır. Gerçek test ölçümlerden önce tüm katılımcılar alıştırma ve ölçüm esnasındaki kuralların gösterilmesi amacıyla reaktif çeviklik protokolünü 3'er kez denemiştir. Ayrıca planlı yön değiştirme protokolü uygulamasında her aday için önceden yerleri belirlenmiş ve numaralarla gösterilen noktaları ezberlemeleri için $2 \mathrm{dk}$. verilmiş ve 5 er kez deneme yapmaları istenmiştir. Birinci ışık uyaranı verildiğinde katılımcı mümkün olan en hızlı şekilde 1şık uyaranın verildiği sensörün altına tekniğe uygun olarak (maksimal hızda yumruk atıp, tekrar adımlama tekniği ile geri gelip, yumruk yanağın hizasına geldiğinde ikinci yumruğa geçmiştir) yumruk atıp daha sonra ikinci uyaranın yandığ ledin altına yumruk atmıştır. Katılımcılar toplam dört ışık uyaranı tamamlandıktan sonra test sona ermiştir.

Reaktif Çeviklik Testi: Katılımcıların reaktif çeviklik değerleri Fitspeed A (Fitmac, Türkiye) cihazıyla ölçülmüştür. Reaktif çeviklik protokolü şekil 1'de görüldüğü gibi kum torbasının üzerine monte edilen aparat sayesinde $30^{\circ}$ aralıklarla dört farklı vuruş noktası tespit edilmiştir.

Sensörlü ledlerin başı vuruş noktalarını görecek şekilde aşağıya bakar olarak aparata monte edilmiştir. Katılımcılar sensörlerin $30 \mathrm{~cm}$. altına yumruk atmışlardır. Bu testte katılımcı hangi sensörün yanacağını bilmemektedir. Katılımcıların reaktif çeviklik protokolündeki $1 s ̧ ı k$ uyaranlarının yerini ezberlememeleri için her katılımcıya farklı senaryolar düzenlenmiştir. Testin toplam süresi istatiksel analiz için kayıt altına alınmıştır. 

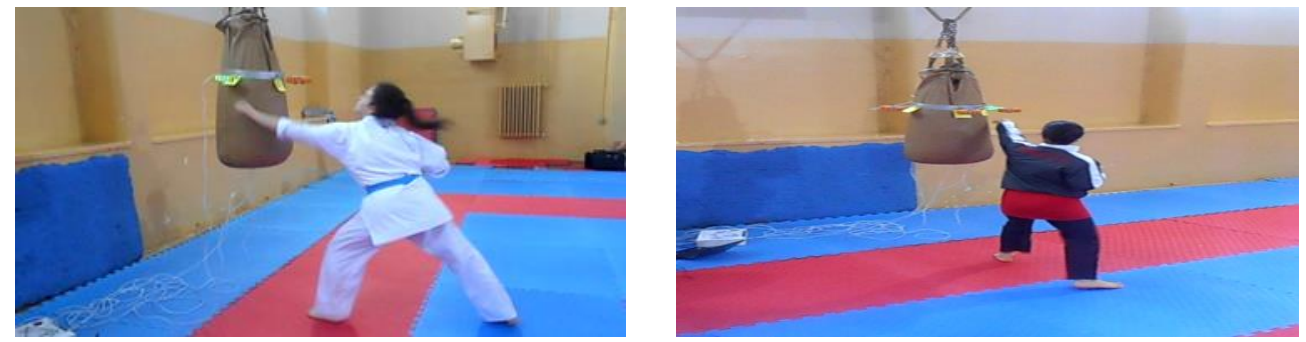

Şekil 1. Sporcunun aktifleşen sensöre doğru tekniğe uygun yumruk atarken görüntüsü

Planlı Çeviklik Testi: Katılımcıların tamamı reaktif çeviklik testinde kendilerine uygulanan senaryonun aynısını bu sefer tüm sensörler üzerine numara yapıştırılmış şekilde (başlangıcı, sonu, yön değiştirme noktaları bilinen) şeklinde uygulanmıştır. Bu test literatürdeki planlı çeviklik testleri gibi herhangi bir görsel strateji ya da bilişsel bir faaliyeti kapsamamaktadır.

\section{İstatistiksel analiz}

Tüm katılımcıların tanımlayıcı istatistikleri analiz edilmiştir. Verilerin normal dağılıp dağılmadığının belirlenmesi için Kolmogorov Smirnov ve homojenliğin belirlenmesi için Levene testleri uygulanmıştır. Verilerin normal dağılım gösterdiği ve homojen olduğu belirlendikten sonra gruplar arasında reaktif ve planlı yön değiştirme değerlerinin karşılaştırılması amacıyla bağımsız değişken t testi kullanılmıştır. Ayrıca her iki test arasındaki ilişkinin belirlenmesi için Pearson Korelasyon analizi uygulanmıştır. Anlamlılık değeri olarak $\mathrm{p}<0.05$ değeri alınmıştır.

\section{BULGULAR}

Tablo 1'de görüldüğü üzere, elit sporcuların reaktif çeviklik süreleri istatistiksel olarak daha kısa $(2.56 \pm 0.77 \mathrm{sn}$ vs. $3.46 \pm 1.21 \mathrm{sn}$ p $<0.05)$, planlı yön değiştirme becerileri arasında anlamlı fark tespit edilememiştir.

Tablo 2'de görüldüğü gibi, reaktif çeviklik ile planlı yön değiştirme becerileri arasında pozitif yönde yüksek bir ilişki tespit edilmiştir (r: 0.823, p<0.05). 
Tablo 1. Elit $(n=13)$ ve sub-elit karatecilerin $(n=10)$ reaktif çeviklik ve planlı yön değiştirme becerilerinin karşılaştırılması

\begin{tabular}{lcc} 
Değişkenler & Elit Sporcular $(\mathbf{n}=\mathbf{1 3})$ & Sub-elit Sporcular $(\mathbf{n}=\mathbf{1 0})$ \\
\hline Reaktif çeviklik $(\mathrm{sn})$ & $2.567 \pm \mathbf{S} \pm \mathbf{S}$ & $3.50^{*}$ \\
\hline & & \\
PYD $(\mathrm{sn})$ & $2.484 \pm 0.52$ & $2.163 \pm 0.63$ \\
\hline
\end{tabular}

$\overline{\bar{X}}$ : Ortalama, SS: Standart sapma, PYD: Planlı Yer Değiştirme, *: $\mathrm{p}<0.05$

Tablo 2. Tüm katılımcıların (n:23) reaktif çeviklik ve planlı yön değiştirme becerileri arasındaki ilişki

\begin{tabular}{lccc}
\hline Değişkenler & $\mathbf{n}$ & $\mathbf{r}$ & $\mathbf{p}$ \\
\hline $\begin{array}{l}\text { Reaktif Çeviklik } \\
\text { PYD }\end{array}$ & 23 &, $874^{* *}$ & 0.001 \\
\hline
\end{tabular}

PYD: Planlı Yer Değiştirme, **: $\mathrm{p}<0.01$

\section{TARTIŞMA VE SONUÇ}

$\mathrm{Bu}$ çalışmanın amacı elit ve sub-elit karatecilerde yumruk atış tekniğine göre düzenlenmiş reaktif çeviklik ile planlı yön değiş̧tirme becerilerinin karşılaştırılması ve iki test arasındaki ilişkinin belirlenmesidir. Çalışma sonunda elit ve sub-elit sporcular arasında planlı yön değiştirme değerleri arasında anlamlı bir fark görülmemişken, reaktif çeviklik test sonuçlarının elit grupta anlamlı olarak daha iyi olduğu tespit edilmiştir. Bununla beraber her iki test arasında yüksek derecede pozitif bir ilişki belirlenmiştir. Elit genç karatecilerin verilen uyaranlara daha kısa sürede yanıt vermeleri bu oyuncuların gereksiz bilgi kaynaklarını göz ardı ederek görsel ve bilgi işlem stratejilerini daha iyi kullandıklarını düşündürtmektedir.

$\mathrm{Bu}$ çalışma ile paralel olarak reaktif testlerde elit sporcuların karar verme hızının sub-elit oyunculara göre daha hızlı olduğunu ortaya koyan birçok çalışma bulunmaktadır (Farrow ve ark., 2005; Gabbett ve Benton, 2009; Serpell ve ark., 2010 ). Örneğin; Gabbett ve Benton'un (2009) reaktif çeviklik testinde karar verme ve hareket hızının elit oyuncularda daha hızlı olduğunu göstermiştir. Benzer şekilde, Serpell ve ark. (2010), elit ve sub-elit rugby oyuncularının spora özgü reaktif çeviklik test değerlerini karşılaştırmışlar ve elit oyuncuların çok daha iyi değerlere 
sahip olduklarını bildirmişlerdir. Reaktif çeviklik performansındaki bu farkı elit oyunculardaki algılama becerileri ve/veya reaksiyon yeteneği farklılıkları ile açıklamışlardır. Benzer şekilde, Gabbett, Kelly ve Sheppard, (2008) elit ve sub-elit ragbi oyuncularında planlı yön değiştirme, sürat ve reaktif çeviklik değerlerini karşılaştırdığı çalışmasında 1. ligdeki oyuncuların hareket ve karar verme sürelerinin 2. ligdeki oyunculara oranla daha iyi olduğunu bildirmiş̧tir. Bununla beraber planlı yön değiştirme değerleri arasında anlamlı bir fark bulamamışlardır.

Algısal karar hızı toplam reaktif çeviklik süresini güçlü bir şekilde etkilemektedir. Örneğin; Young ve Willey, toplam reaktif çeviklik zamanı ile algısal karar verme süresi arasında çok yüksek bir korelasyon $(r=0.77, p<0.00)$ belirlemişlerdir. Bu ilişki toplam süreyle hareket hızı arasında daha düşüktür $(\mathrm{r}=0,59)$. Bu nedenle, araştırmacılar çeviklik test ve antrenmanlarına algılama becerilerinin dahil edilmesini önermiş̧lerdir. Farrow ve ark., (2005), yüksek, orta ve düşük seviye netball oyuncularında dış uyaran olarak video gösterimi kullandıkları reaktif çeviklik testi ile planlı çeviklik testini karşılaştırmışlardır. Her iki testte yaklaşık olarak \%50 $\left(r^{2}=0.49\right)$ ortak varyansı paylaşmışlardır. $\mathrm{Bu}$ da planlı ve reaktif çeviklik testlerin benzer durumları fakat farklı becerileri ölçtüğünü göstermektedir. Oliver ve Meyers (2009), dışarıdan 1şık uyaranı vererek oluşturdukları reaktif çeviklik testi ile planlı çeviklik testini karşılaştırmışlardır. Analizler sonucunda her iki çeviklik protokolü arasında yüksek derecede ortak varyansı göstermiştir $\left(\mathrm{r}^{2}=\right.$ 0.87). Bulgular her ne kadar reaktif testin planlı testten daha yavaş olduğunu gösterse de, her iki testte benzer baskın fiziksel özellikleri ölçmektedir.

Spor Bilimlerinde yetenek sürekli olarak sportif performans üstünlüğü olarak tanımlanmıştır. Her ne kadar motorik performans rahatlıkla gözlemlenebilirken bunun içinde performansa katkı sağlayan algısal ve bilişsel mekanizmalar çok az aydınlatılabilmiştir. Algısal ve bilişsel beceri var olan bilgi ile entegrasyon için çevresel bilginin elde edilmesi ve anlamlandırılması ve tercihler üretilmesi, bunun sonucunda bunlar içinden seçilen ve uygulanan en uygun yanıtın verilmesi ile ilgili kabiliyet olarak tanımlanır (Mann, Williams, Ward ve Janelle, 2007). Çeviklik performansı yukarıda bahsedildiği gibi hem fiziksel hem de zihinsel süreçlerin hızlılığına ve doğruluğuna bağlıdır. Her spor dalında olduğu gibi karate gibi dövüşs sporlarında da antrenman veya müsabaka sırasındaki birçok durumda algılayıcılar tarafından ortamdan elde edilen bilginin beyinin üst merkezlerinde işlenmesi gerekmektedir. Elde edilen bu bilgilerdeki karmaşıklık çoğaldıkça beyinin ilgili bölgelerindeki bilişsel işlem ve sonuç davranışın ortaya 
çıkması esnasında geçen süre artış ortaya çıkmaktadır (Karacabey, 2013). Başarılı bir Performans açısından nereye ve ne zaman bakılacağı hayati önem taşır. Yapılacak iş ile ilgili birçok gerekli ve gereksiz bilgi bulunmaktadır. Sporcu alandaki bu kadar çok bilgiyi anlamlandırabilmek, dikkatini uygun alana yöneltip bu alandan verimli ve etkili sonucu almak zorundadır (Mann ve ark., 2007). Sonuç olarak; çevikliğin arttırılması ya da test edilmesi amacıyla yapılan faaliyetlerde görsel strateji ve bilişsel işlemlerinde dahil edilmesinin çok daha faydalı olacağı düşünülmektedir.

\section{KAYNAKLAR}

Appelbaum, L. G., \& Erickson, G. (2018). Sports vision training: a review of the state-of-the-art in digital training techniques. International Review of Sport and Exercise Psychology, 11(1), 160-189.

Barnes, J. L., Schilling, B. K., Falvo, M.J., Weiss, L.W. \& Creasy, A. K. (2007). Relationship of jumping and agility performance in female volleyball athletes. Journal of Strength \& Conditioning Research, 21(4), 1192-6.

Farrow, D., Young, W. \& Bruce, L. (2005). The development of a test of reactive agility for netball: A new methodology. Journal of Science and Medicine in Sport, 8(1), 52-60.

Gabbett, T. J., Kelly, J. N., \& Sheppard, J. M. (2008). Speed, change of direction speed, and reactive agility of rugby league players. Journal of Strength \& Conditioning Research, 22(1), 174-181.

Gabbett, T. \& Benton, D. (2009). Reactive agility of rugby league players. Journal of Science and Medicine in Sport, 12(1), 212214.

Hertel, J., Denegar, C.R., Johnson, P.D., Hale, S.A. \& Buckley, W.E. (1999). Reliability of the Cybex Reactor in the Assessment of an Agility Task. Journal of Sport Rehabilitation, 8(1), 24-31.

Holmberg, P. M. (2009). Agility training for experienced athletes: A dynamical systems approach. Strength and Conditioning Journal, 31(5), 73-78.

Jeffreys, I. A. (2011). Task-Based Approach to Developing Context-Specific Agility. Strength and Conditioning Journal, 3(4), 1524-1602.

Karacabey, K. (2013). Sporda performans ve çeviklik testleri. International Journal of Human Sciences, 10(1), 1693-1704.).

Mann, D.T.Y., Williams, A. M., Ward, P. \& Janelle M. C. (2007). Perceptual-Cognitive Expertise in Sport: A Meta-Analysis. Journal of Sport \& Exercise Psychology, 29(4), 457-478.

Oliver, J. \& Meyers, R. W. (2009). Reliability and generality of measures of acceleration, planned agility, and reactive agility. International Journal of Sports Physiology Performance, 4(3), 345-354.

Serpell, B.G., Ford, M. \& Young, W.B. (2010). The development of a new test of agility for rugby league. J Strength Cond Res, 24(12), 3270-3277.

Sheppard, J. M. \& Young, W. B. (2006). Agility literature review: Classifications, training and testing. Journal of Sports Sciences, 24(9), 919-932.

Young W.B., James, R. \& Montgomery, J.R. (2002). Is muscle power related to running speed with changes of direction? Journal of Strength \& Conditioning Research, 42(3), 282-288. -1248.

Young, B.W. \& Willey, B. (2010). Analysis of a reactive agility field test. Journal of Science and Medicine in Sport, 13(3), 376378

Young, W., Farrow, D., Pyne, D., McGregor, W. \& Handke, T. (2011). Validity and reliability of agility tests in junior Australian football players. Journal of Strength \& Conditioning Research, 25(12), 3399-3403.

Young, W. \& Farrow, D. (2006). A Review of Agility: Practical Applications for strenght and conditioning. Strength \& Conditioning Journal, 28(5), 24-38.

Zemkova, E. (2016). Differential Contribution of Reaction Time and Movement Velocity to the Agility Performance Reflects Sport-Specific Demands. Human Movement, 17(2), 94-101. 